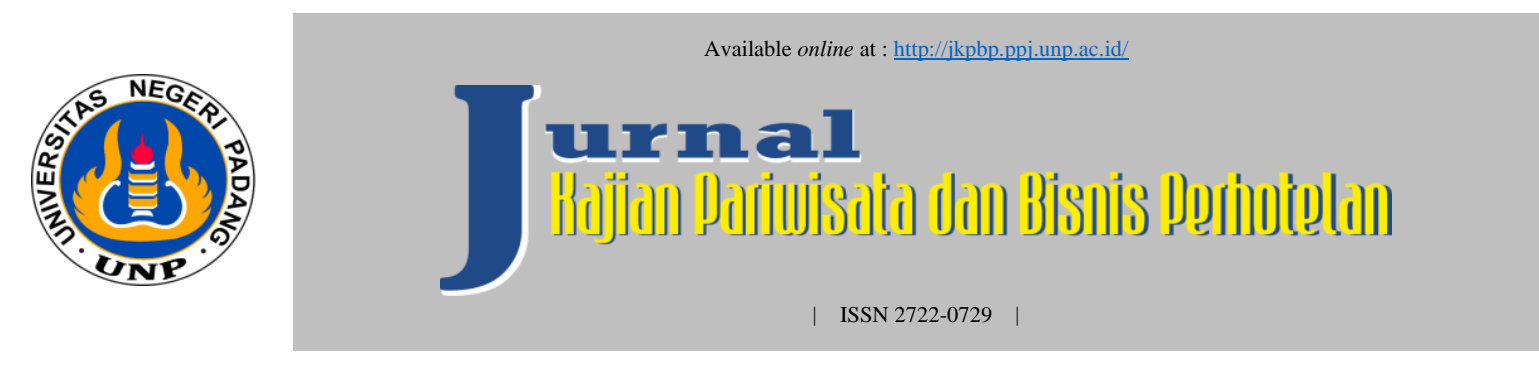

\title{
Karakteristik Wisatawan Di Daya Tarik Wisata Simpang Tigo Buayo Putiah Nagari Taratak Kabupaten Pesisir Selatan
}

\author{
Jeki Martin ${ }^{1}$, Trisna Putra ${ }^{2}$ \\ ${ }^{1}$ Universitas Negeri Padang \\ ${ }^{2}$ Universitas Negeri Padang \\ email : tputra@fpp.unp.ac.id
}

\begin{abstract}
ABSTRAK
Penelitian tentang Karakteristik Pengunjung di Daya tarik Wisata Simpang Tigo Buayo Putiah bermula dari permasalahan yang penulis temukan yaitu belum diketahuinya karakteristik pengunjung di Daya tarik wisata Simpang Tigo Buayo Putiah. Dan penelitian ini juga dilandasi dari kebutuhan Dinas Pariwisata Pesisir Selatan dalam mendata karakteristik pengunjung yang datang ke Daya tarik wisata. Berdasarkan permasalahan tersebut penulis ingin meneliti dengan tujuan ingin mengetahui Karakteristik Pengunjung Di Daya wisata Simpang Tigo Buayo Putiah.

Jenis penelitian adalah penelitian deskriptif kuantitatif dengan menggunakan metode survei. Dalam penelitian ini sampel diambil dengan memakai teknik non probability sampling,penelitian ini memiliki sampel berjumlah 100 orang. Pengumpulan data menggunakan angket yang disusun berdasarkan skala guttman, data pada penelitian diolah dengan bantuan program Microsoft Excel 2010.

Dari beberapa langkah yang dilakukan pada saat penelitian maka didapatkan hasil penelian yaitu : (1) Berdasarkan Karakteristik Demografis Mayoritas pengunjung berusia 18-24 tahun dan mayoritas pengunjung perempuan, dengan tingkat pendidikan SMA/Sederajat,dengan mayoritas pekerjaan yaitu Pelajar/Mahasiswa, dengan mayoritas pendapatan $<1.500 .000$ dan Status perkawinannya mayoritas masih lajang/belum menikah.(2) Berdasarkan Karakteristik Geografisnya pengunjung didominasi dari dalam area Pesisir Selatan dengan jarak tempat tinggal ke Daya tarik wisata $\geq 20 \mathrm{~km}$, mayoritas tinggal di daerah pantai dan berlokasi di area perumahan padat penduduk dengan jumlah.(3) Berdasarkan Karakteristik Psikografis mayoritas pengunjung dengan tipe psychocentric dengan jumlah sebanyak 52\% dan $48 \%$ wisatawan dengan tipe allocentric.
\end{abstract}

Kata kunci : Karakteristik Wisatawan, Daya Tarik wisata 


\section{PENDAHULUAN}

Pariwisata indonesia saat ini terus berusaha untuk mengembangkan kegiatan kepariwisataan yang ada. Hal ini dilakukan karena semakin banyaknya arus pergerakan manusia dalam melakukan perjalanan untuk tujuan rekreasi, dalam pendapat [1] Pariwisata merupakan kegiatan perjalanan yang memilki tujuan sebagai liburan dan rekreasi, ditunjukan pada perjalanan yang sementara dan singkat dari individu atau kelompok orang ke suatu daerah tujuan yang berada di luar kegiatan. Pariwisata Indonesia pada era sekarang ini mulai dijamah wisatawan luar negeri maupun wisatawan dalam negeri, hal ini tidak terlepas dari keindahan dan keunikan yang terdapat pada daya tarik wisata.

Daya tarik wisata memiliki keunikan daya tarik untuk dikunjungi dan mempunyai nilai lebih . [2] Daya tarik wisata sebuah objek dengan segala daya tariknya dapat dinikmati yang layak untuk dijual kepada wisatawan. Dengan adanya daya tarik wisata ini akan banyak pengunjung datang untuk berwisata, bermacam bentuk tujuan wisata seperti wisata belanja, wisata alam, wisata religi maupun wisata budaya yang akan menarik perhatian pengunjung.

Pengunjung merupakan unsur utama dalam pariwisata. Pengunjung digolongkan dalam 2 golongan yaitu wisatawan dan pelancong, dari pendapat [3]Wisatawan merupakan seseorang yang sedang melakukan perjalanan dengan tujuan wisata bukan untuk mencari nafkah. pengunjung sangat perlu diperhatikan dalam mengelola kawasan wisata agar dapat memberikan pelayanan dan kenyamanan kepada pengunjung agar pengunjung tertarik untuk datang mengunjungi objek wisata yang dikelola,salah satu faktor yang dipertimbangkan untuk mendatangkan pengunjung adalah dengan mengetahui karakteristik pengunjungnya.

Karakteristik dengan asal kata karakter yang berarti sifat kejiwaan seseorang,tingkah laku maupun budi pekerti yang menjadi pembeda seseorang dengan orang lain. Pendapat [4] Karakter yaitu suatu gambaran khas oleh suatu benda atau individu yang menyatu dalam kepribadian sebuah benda maupun individu tersebut dan menjadi mesin penunjang seseorang dalam mengambil tindakan, berujar, bersikap, dan menanggapi sesuatu. Karakteristik pengunjung dapat ditinjau secara garis besar berdasarkan tiga kelompok yaitu karakteristik demografis, karakteristik geografis, dan karakteristik psikografis. Agar dapat memahami keinginan pengunjung yang datang berkunjung ke suatu daya tarik wisata memahami karakter mereka sangatlah penting, sesuai pendapat [5] memiliki beberapa karakteristik utama yang diketahui dan digunakan dalam merangkai pembangunan kegiatan wisata yang berkelanjutan, mengembangkan serta mengelola kegiatan dalam memasarkan dan mempromosikan atraksi wisata.

Keberagaman karakteristik pengunjung ini dapat ditemui di berbagai daerah, salah satunya berada di Provinsi Sumatera Barat, sebagai salah daerah potensial wisata di indonesia yang memiliki banyak potensi tujuan wisata salah satunya Kabupaten Pesisir Selatan, dengan garis pantai lebih kurang 218 kilometer. Kabupaten Pesisir Selatan merupakan daerah yang kaya dengan objek wisata, seperti objek wisata Pantai Carocok Painan, Kawasan Mandeh, Jembatan Akar, Pantai Batu Kalang, Bukit Langkisau serta Daya tarik wisata Simpang Tigo Buayo Putiah. Salah satunya adalah objek wisata pantai yang terdapat di Kabupaten Pesisir Selatan adalah Daya tarik wisata Simpang Tigo Buayo Putiah yang lokasinya berada pada Nagari Taratak, Kecamatan Sutera, Pesisir Selatan.

Daya tarik Wisata Simpang Tigo Buayo Putiah terletak di Nagari Taratak, Kecamatan Sutera. Lokasinya berjarak sekitar $30 \mathrm{Km}$ dari kota Painan. Daya tarik wisata Simpang Tigo Buayo Putiah dibuka pada akhir tahun 2017 dan sudah menjadi tujuan wisata baru bagi wisatawan baik dalam daerah maupun luar daerah Kabupaten Pesisir Selatan. Dengan ini bisa dilihat pada tabel jumlah kedatangan pengunjung ke Daya tarik wisata Simpang Tigo Buayo Putiah yaitu : 
Tabel 1. Jumlah kunjungan wisatawan

\begin{tabular}{|c|c|c|}
\hline No & Tahun & Jumlah kunjungan wisatawan \\
\hline 1 & 2018 & 20.592 \\
\hline 2 & 2019 & 24.675 \\
\hline 3 & 2020 & 9.435 \\
\hline
\end{tabular}

Berdasarkan data diatas dapat dilihat bahwa kunjungan menuju Daya tarik wisata Simpang Tigo Buayo Putiah meningkat pada tahun 2019 namun menurun di tahun 2020 dikarenakan adanya pandemi covid-19. Permasalahan dalam penelitian yang penulis lakukan yaitu belum jelasnya karakteristik pengunjung di kawasan daya tarik wisata, belum adanya data karakteristik pengunjung di dinas Pariwisata, pengembangan fasilitas wisata belum sesuai dengan karakteristik pengunjung, belum jelas target pemasaran dari kawasan, sulitnya menetapkan tren pariwisata yang ada pada kawasan. Sehingga perlu dilakukan penelitian dengan tujuan agar dapat memberikan masukan dan saran kepada pihak terkait dalam pengelolaan dan pengembangan daya tarik wisata.

\section{METODOLOGI}

Berdasarkan metode yang dipakai pada penelitian, termasuk kedalam penelitian deskriptif kuantitatif menggunakan metode survei. Data yang telah didapatkan selanjutnya dilakukan analisis sesuai dengan maksud dan pernyataan penelitian yang telah dikemukakan. Pendapat [6]penelitian deskriptif yaitu penelitian memiliki tujuan mengumpulkan informasi berdasarkan situasi suatu kondisi gejala, yakni gejala berdasarkan yang terjadi pada saat penelitian dilaksanakan.

Teknik mengambil sampel menggunakan non probability sampling [7], non probability sampling merupakan cara memperoleh sampel yang tidak memiliki peluang maupun kesempatan yang sama bagi setiap komponen maupun anggota populasi yang menjadi sampel. Penggunaan teknik dalam pengumpulan sampel yaitu memakai teknik purposive sampling. Pengumpulan data penelitian yaitu menggunakan komunikasi tidak langsung melalui cara penyebaran angket atau kuesioner.[8]kuesioner merupakan suatu teknik mengumpulkan data menggunakan cara memberikan beberapa pernyataan dalam bentuk tertulis yang diberikan terhadap responden agar dijawab. Penelitian ini memakai kuesioner terstruktur meliputi pertanyaan tertutup, yaitu menggunakan skala guttman dengan memberikan jawaban yang tegas, yaitu"Ya" dan "Tidak". Data pada penelitian ini diolah menggunakan program Microsoft Excel 2010.

Teknik analisis data penelitian ini yaitu metode analisis deskriptif kuantitatif. pendapat [9]Metode analisis deskriptif yaitu penelitian yang tidak termasuk eksperimen, sebab bukan bertujuan mengetahui akibat dari sebuah tindakan. 


\section{HASIL DAN PEMBAHASAN}

\section{A. Hasil Penelitian}

\section{Karakteristik Demografis Wisatawan}

a) Klasifikasi Usia

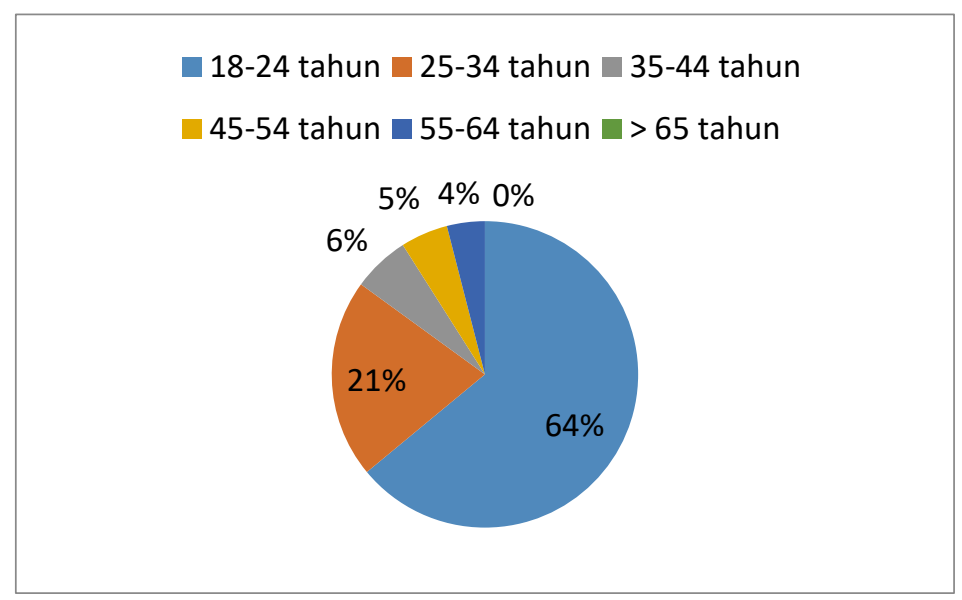

\section{Gambar 1. Klasifikasi Usia}

Dari hasil penelitian melalui kuesioner terhadap 100 responden sebanyak $64 \%$ pengunjung berada pada rentang umur 18-24 tahun,diikuti oleh pengunjung berumur 25-34 tahun sebanyak $21 \%$, selanjutnya pengunjung dengan rentang umur 35-44 tahun sebanyak 6\%, 45 54 tahun sebanyak 5\% dan sisanya adalah pengunjung dengan rentang umur 55-64 sebanyak $4 \%$

\section{b) Jenis Kelamin}

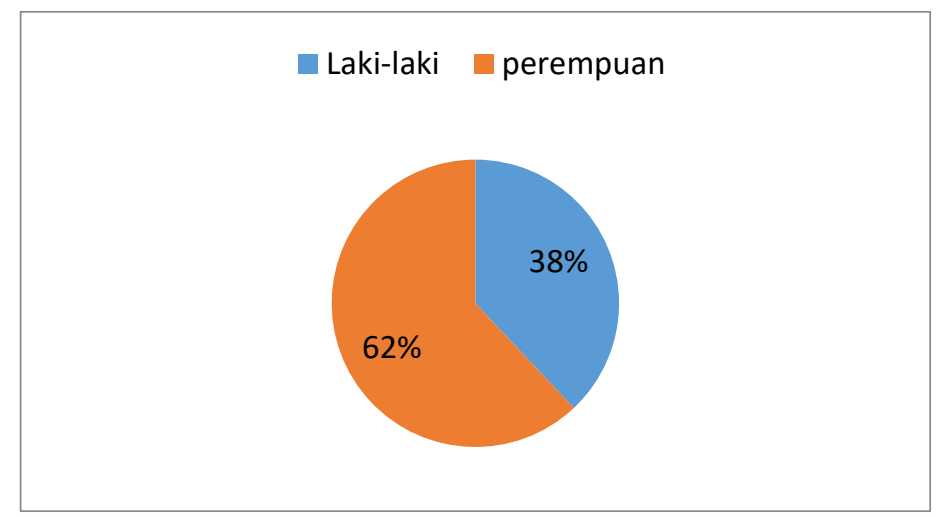

Gambar 2. Jenis kelamin

Dari hasil penelitian berdasarkan jenis kelaminnya didominasi oleh pengunjung berjenis kelamin perempuan dengan jumlah persentase sebanyak $62 \%$ dan $38 \%$ pengunjung laki-laki. 


\section{c) Tingkat Pendidikan}

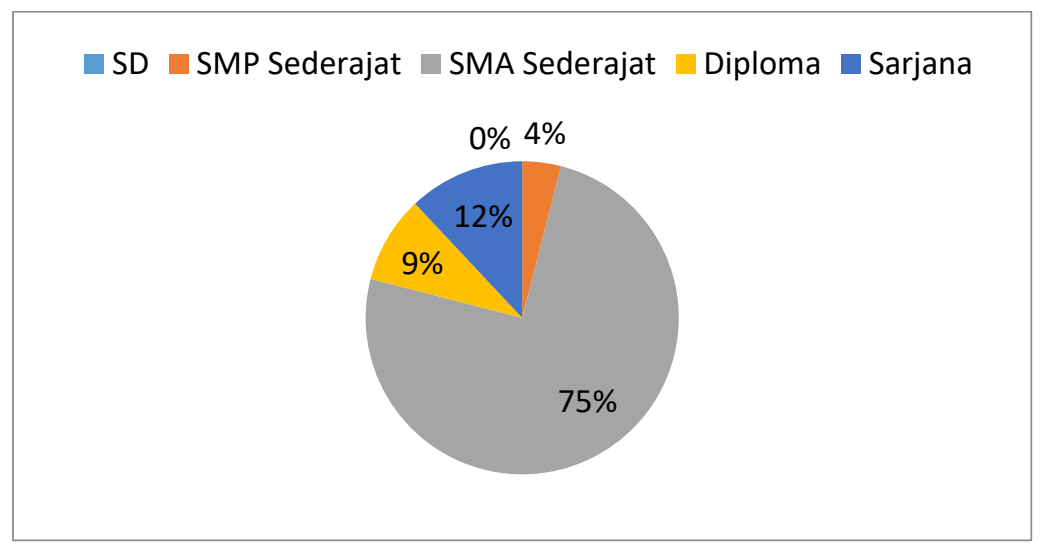

Gambar 3. Tingkat Pendidikan

Berdasarkan tingkat pendidikannya $75 \%$ pengunjung tamat SMA/Sederajat, sebanyak 9\% yang telah Diploma, 12\% Sarjana, dan sisanya sebanyak 4\% Tamat SMP/Sederajat

\section{d) Pekerjaan}

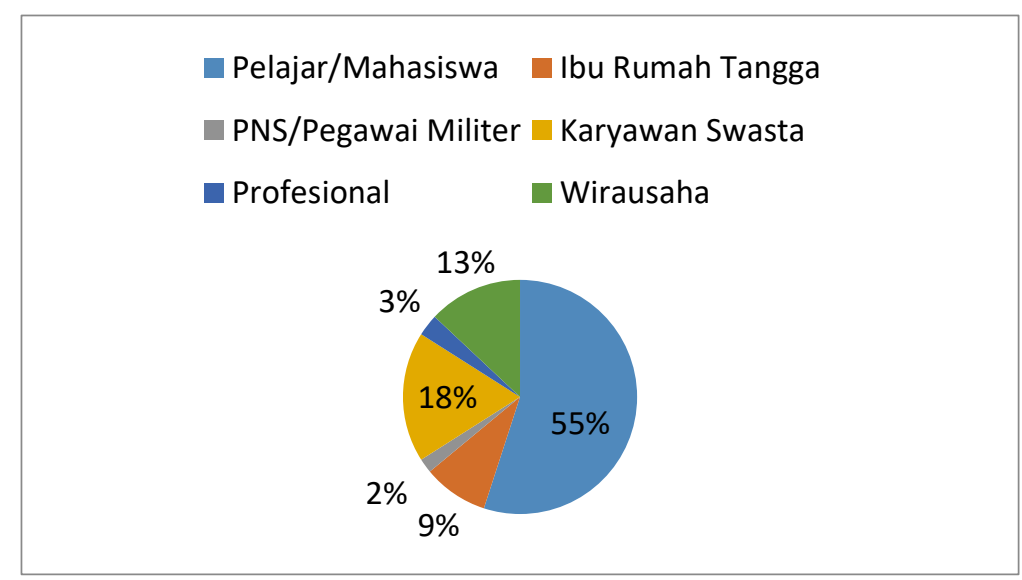

Gambar 4. Pekerjaan

Dari hasil penelitian dapat dijelaskan pekerjaan wisatawan yang berkunjung ke Daya tarik wisata Simpang Tigo Buayo Putiah, dari 100 orang responden sebanyak 55\% masih duduk di bangku sekolah atau perkuliahan intinya masih berstatus sebagai pelajar/mahasiswa, selanjutnya sebanyak 18\% karyawan swasta, 13\% wirausaha, 9\% Ibu rumah tangga, 3\% Profesional dan sisanya sebanyak 2\% PNS/Pegawai militer.

\section{e) Pendapatan}

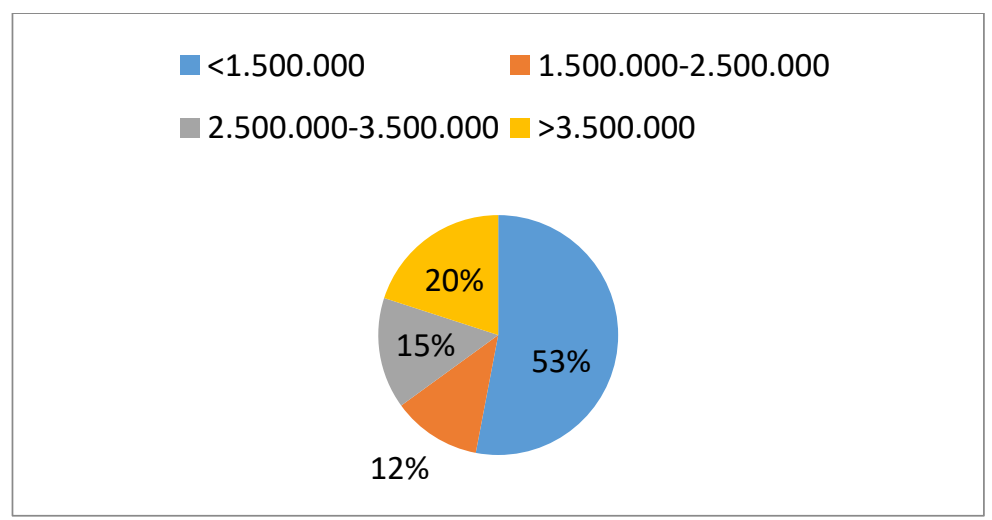

Gambar 5. Pendapatan 
Berdasarkan pendapatannya sebanyak $53 \%$ wisatawan memiliki penghasilan $<1.500 .000$, selanjutnya $20 \%$ pengunjung berpenghasilan $>3.500 .000,15 \%$ dengan penghasilan 2.500.000-3.500.000 dan sisanya sebanyak $12 \%$ pengunjung dengan penghasilan 1.500.000-2.500.000.

\section{f) Status Perkawinan}

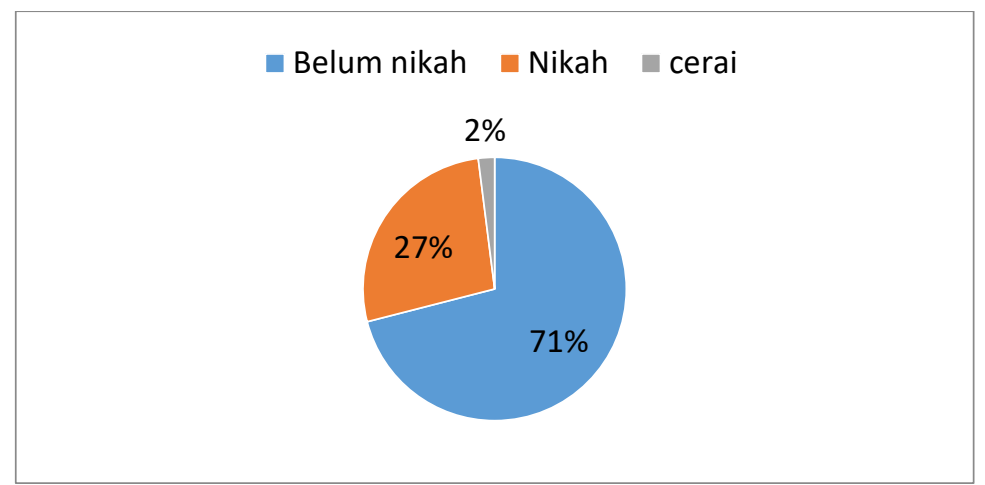

Gambar 6. Status Perkawinan

Dari hasil penelitian dapat dijelaskan status perkawinan wisatawan yang berkunjung ke objek wisata simpang tigo buayo putiah. Sebanyak $71 \%$ belum menikah, $27 \%$ yang sudah menikah, dan $2 \%$ dengan status cerai.

\section{Karakteristik Geografis}

\section{a) Kota Tempat Tinggal}

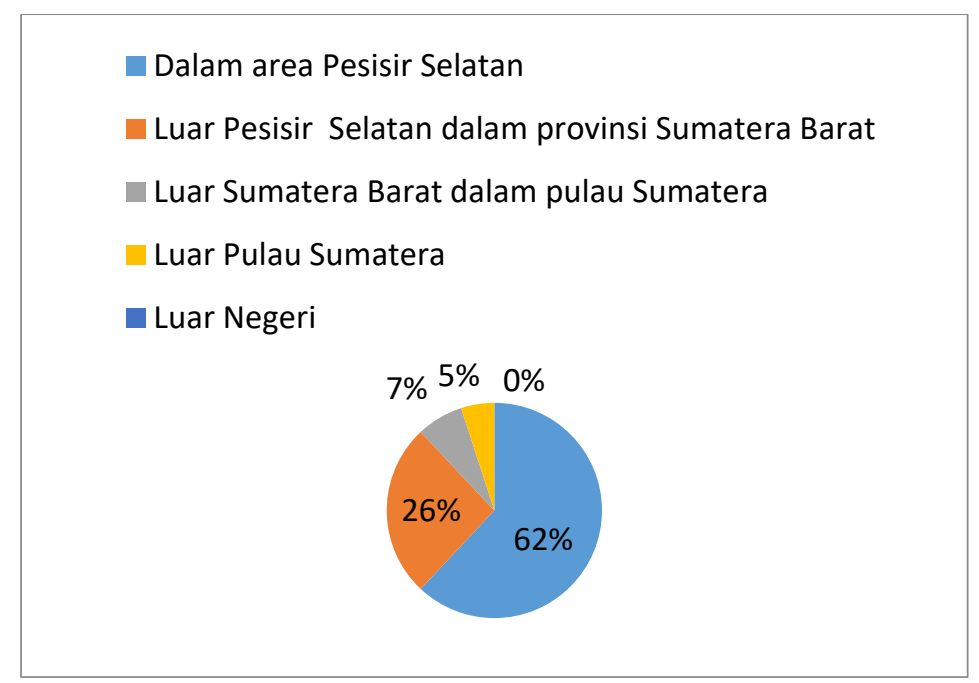

Gambar 7. Kota Tempat Tinggal

Dari hasil penelitian berdasarkan kota tempat tinggalnya pengunjung paling dominan berasal dari dalam area pesisir selatan yaitu sebanyak $62 \%$, selanjutnya sebanyak $26 \%$ berasal dari luar pesisir selatan masih dalam provinsi sumatera barat, $7 \%$ pengunjung berasal dari luar sumatera barat masih dalam pulau sumatera, dan sisanya sebanyak $5 \%$ pengunjung berasal dari luar pulau sumatera, dan sebanyak $0 \%$ pengunjung dari luar negeri dengan artian tidak ada wisatawan luar negeri yang berkunjung ke Daya tarik wisata Simpang Tigo Buayo Putiah. 


\section{b) Jarak Tempat Tinggal ke Objek Wisata Simpang Tigo Buayo Putiah}

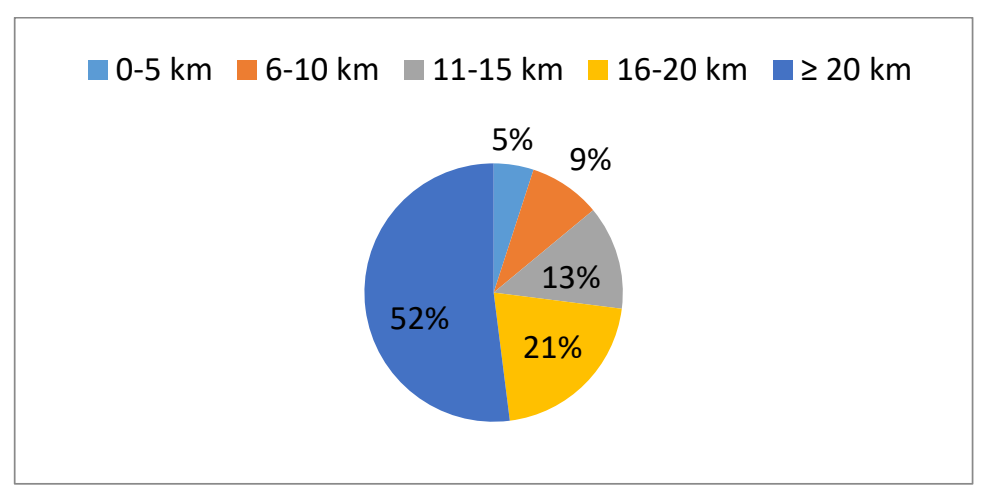

Gambar 8. Jarak Tempat Tinggal Ke Objek Wisata

Simpang Tigo Buayo Putiah

Dari hasil penelitian berdasarkan jarak tempat tinggal ke Daya tarik Wisata Wisata Simpang Tigo Buayo Putiah. Sebanyak 52\% pengunjung menjawab $\geq 20 \mathrm{~km}$, dan selanjutnya $21 \%$ pengunjung yang berjarak $16-20 \mathrm{~km}, 13 \%$ dengan jarak $11-15 \mathrm{~km}, 9 \%$ pengunjung dengan jarak 6-10 km, dan sisanya sebanyak 5\% wisatawan yang berjarak 0-5 $\mathrm{km}$.

c) Kondisi Geografis tempat Tinggal

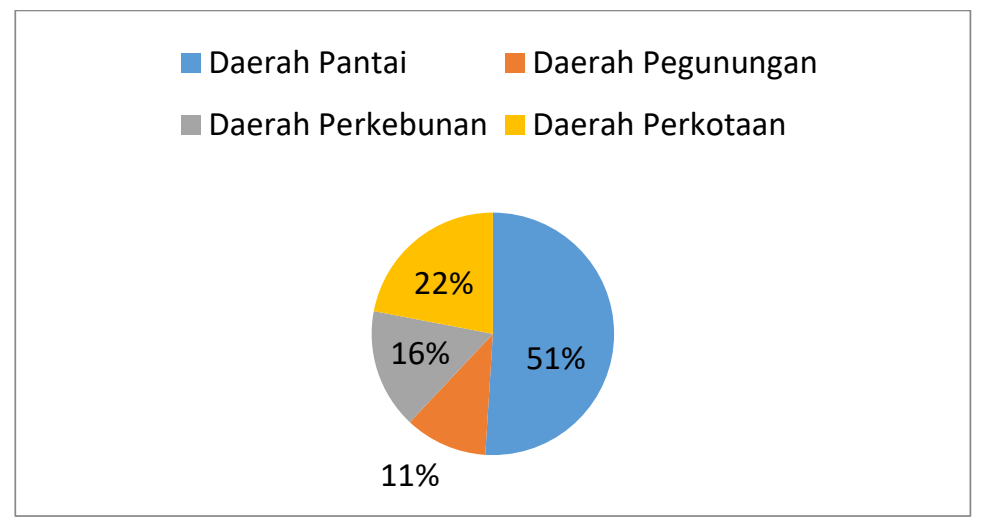

Gambar 9. Kondisi Geografis Tempat Tinggal

Berdasarkan kondisi geografis tempat tinggalnya sebanyak $51 \%$ pengunjung tinggal di daerah pantai, $22 \%$ di daerah perkotaan, $16 \%$ di daerah perkebunan, dan $11 \%$ pengunjung tinggal di daerah pegunungan

\section{d) Lokasi Tempat Tinggal}

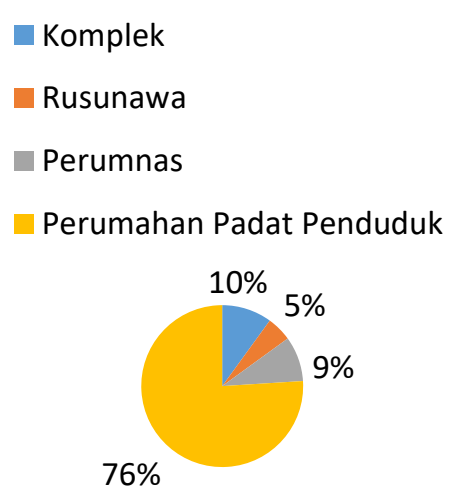

Gambar 10. Lokasi Tempat Tinggal 
Berdasarkan lokasi tempat tinggalnya dari 100 orang responden $76 \%$ responden berlokasi di area perumahan padat penduduk, 10\% berlokasi tinggal di komplek, 9\% tinggal di perumnas, dan sisanya $5 \%$ pengunjung tinggal di rusunawa.

\section{Karakteristik Psikografis}

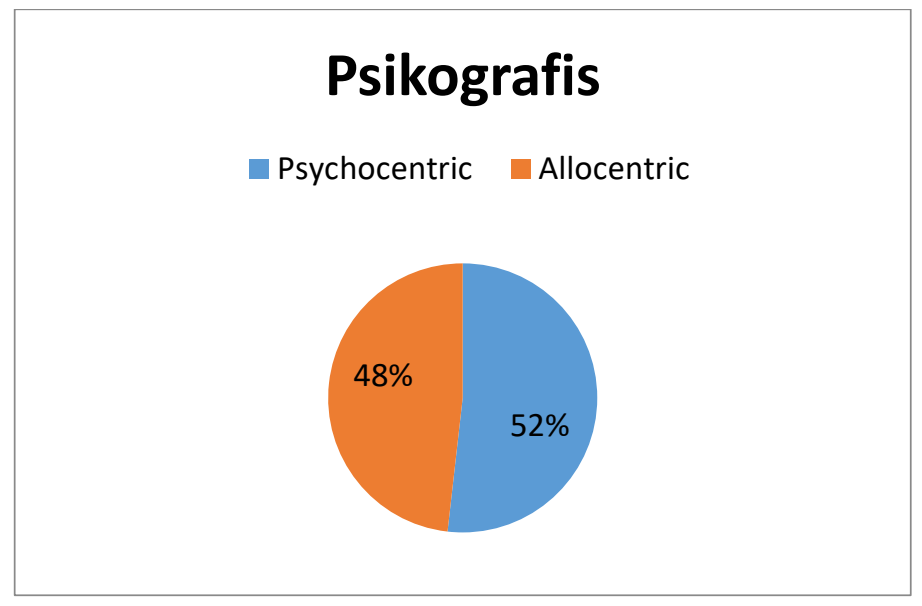

Gambar 11. Karakteristik Psikografis

Berdasarkan hasil penelitian karakteristik psikografis pengunjung didominasi oleh pengunjung dengan tipe psychocentric sebanyak 52\% dan pengunjung dengan tipe allocentric sebanyak $48 \%$.

\section{B. Pembahasan}

\section{Karakteristik Demografis}

Dari sebanyak 100 responden mayoritas pengunjung yang berkunjung ke Objek Wisata Simpang Tigo Buayo Putiah adalah yang berusia 18-24 tahun.Berdasarkan penggolongan usia pengunjung yang datang ke daya tarik wisata Simpang Tigo Buayo Putiah termasuk ke dalam kelompok anak muda dengan usia pengunjung diatas 18 tahun, usia pada kelompok ini sudah banyak mulai berpikir dengan logika daripada emosi. dengan mayoritas pengunjung berjenis kelamin perempuan yaitu sebanyak $62 \%$,berdasarkan tingkat pendidikannya mayoritas lulusan SMA/Sederajat dengan jumlah $75 \%$, dan mayoritas pekerjaannya adalah pelajar/mahasiswa yaitu sebanyak 55\%, dengan pendapatan perbulan $<1.500 .000$ bahkan tidak memiliki pendapatan sama sekali, hal tersebut menunjukan sesuai dengan pendapat [10] berwisata menjadi kebutuhan utama bagi mereka dibandingkan membeli barang mobil atau rumah. Pendapatan pada umumnya saling terkait dengan pendidikan, pekerjaan dan usia dengan artian, pengunjung yang memiliki penghasilan tinggi cenderung memiliki pendidikan yang tinggi dan pekerjaan yang memadai dengan usia tertentu, pendapatan sangat berpengaruh kepada pola berwisata terutama waktu yang tersedia untuk berwisata. berdasarkan status perkawinannya sebanyak $71 \%$ pengunjung berstatus masih lajang atau belum menikah.

\section{Karakteristik Geografis}

Berdasarkan hasil penelitian mayoritas wisatawan yaitu yang tinggal di area pesisir selatan dengan jumlah $62 \%$ dengan mayoritas jarak tempat tinggal ke daya tarik wisata yaitu $\geq 20 \mathrm{~km}$, dengan ini menunjukan bahwa pengunjung yang datang ke daya tarik wisata Simpang Tigo Buayo Putiah tidak hanya berasal dari daerah terdekat dengan Daya tarik wisata Simpang Tigo Buayo Putiah. dan $51 \%$ pengunjung dengan kondisi geografis tempat tinggalnya berada di daerah pantai, dikarenakan mayoritas pengunjung adalah yang berasal dalam area Pesisir Selatan yang merupakan daerah pesisir yang membentang sepanjang pantai bagian selatan 
Sumatera Barat, maka kondisi geografis tempat tinggalnya mayoritas adalah daerah pantai, dan mayoritas lokasi tempat tinggalnya adalah di perumahan padat penduduk/perkampungan.

\section{Karakteristik Psikografis}

Berdasarkan hasil penelitian mayoritas pengunjung di Daya tarik Wisata Simpang Tigo Buayo Putiah merupakan pengunjung dengan tipe psychocentric yaitu dengan jumlah persentase sebanyak 52\%, dan sisanya masuk kedalam tipe allocentric yaitu sebanyak $48 \%$. Psikosentrik atau Psychocentric, dengan asal kata 'psyche' yang berarti terpusat. Pengunjung yang termasuk dalam kategori Psikosentrik umumnya terfokus perjalanannya pada satu tema, topik atau tujuan. Mereka memilih daerah tujuan wisata yang sudah dikenal dan menjadi ikon, dan mereka digolongkan dalam pendapatan rendah. Mereka tidak mempunyai jiwa berpetualang dan menghendaki fasilitas yang lengkap dan memadai. Mereka cenderung enggan dalam melakukan lintas budaya. Sedangkan Allosentrik atau Allocentric asal kata 'allo' yang berarti bervariasi. Pengunjung pada tipe allocentric merupakan pengunjung yang menyenangi berbagai kegiatan wisata. Mereka melakukan perjalanan dengan tujuan mencari perbedaan budaya dan lingkungan, pada umumnya mereka memiliki pendapatan yang tinggi. Adrenalin berpetualang harus tertantang, semangat wisata mereka menggebu-gebu. Mereka seringkali tidak memanfaatkan fasilitas di kawasan wisata dan lebih memilih merasakan tinggal bersama masyarakat di kawasan wisata. Dari hasil tersebut menunjukan bahwa pengunjung yang datang ke daya tarik wisata Simpang Tigo Buayo Putiah tergolong ke dalam tipe psychocentric yaitu pengunjung masih menggemari wisata yang masih erat dengan kehidupan sehari-harinya dan lebih memilih kegiatan wisata pada kawasan yang menjadi ikon dan ramai dikunjungi pengunjung.

\section{KESIMPULAN}

Hasil Penelitian yang telah diketahui pada bagian hasil dan pembahasan sebelumnya maka dapat disimpulkan mengenai Karakteristik Pengunjung di Daya Tarik Wisata Simpang Tigo Buayo Putiah.

1. Mayoritas pengunjung yang berkunjung ke Daya tarik wisata Simpang Buayo Putiah adalah pengunjung yang berumur 18-24 tahun yaitu sebanyak 64\% dari 100 responden,berdasarkan jenis kelaminnya didominasi oleh pengunjung perempuan sebanyak $62 \%$,Berdasarkan tingkat pendidikan terakhir yang didapatkan mayoritas SMA/Sederajat. Pekerjaan Mayoritas pengunjung masih dalam bangku sekolah dan perkuliahan,pendapatan yang diperoleh yaitu < 1.500.000 dan bahkan tidak memiliki pendapatan sama sekali karena masih berstatus sebagai pelajar/mahasiswa dan belum menikah.

2. Berdasarkan karakteristik geografisnya pengunjung yang banyak berkunjung ke daya tarik wisata Simpang Tigo Buayo Putiah berasal dari dalam area Pesisir Selatan yaitu sebanyak $62 \%$ dengan jarak tempat tinggal pengunjung ke objek wisata $\geq 20 \mathrm{~km}$. Kondisi geografis daya tarik mayoritas daerah pantai dan berlokasi di perumahan padat penduduk atau perkampungan.

3. Berdasarkan Karakteristik Psikografis Pengunjung yang berwisata ke Daya tarik wisata Simpang Tigo Buayo Putiah di dominasi oleh pengunjung dengan tipe psychocentric yaitu dengan jumlah $52 \%$ dan $48 \%$ lainnya adalah pengunjung dengan tipe allocentric 


\section{DAFTAR PUSTAKA}

[1] D. N. Imanita, F. I. Sosial, and F. I. Sosial, "PROSEDUR TENDER EVENT JAKARTA NIGHT FESTIVAL OLEH DINAS PARIWISATA DAN,” vol. 1, no. 1, pp. 76-94, 2019.

[2] E. Junaida, "Pengaruh Daya Tarik Wisata dan Word Of Mouth terhadap Keputusan Wisata Berkunjung ke Taman Hutan Kota di Kota Langsa," J. Samudra Ekon. dan Bisnis, vol. 10, no. 2, pp. 146-155, 2019, doi: 10.33059/jseb.v10i02.1317.

[3] Ridwan. Mohamad. 2019. Perencanaan Pengembangan Daerah Tujuan Pariwisata.Yogyakarta: CV BUDI UTAMA.

[4] S. Artikel and W. Aladin, "Jurnal Pendidikan Bahasa dan Sastra Daerah ALADIN SUNTINGAN RANY FEBRIANI UNTUK BAHAN AJAR BERBASIS KARAKTER DI TINGKAT SMA / SMK / MA Siti Nur' azizah, Rany Febriani Program Studi Pendidikan Bahasa dan Sastra Daerah STKIP Muhammadiyah Kuningan Gedung A Lt . 3 Kuningan Jawa Barat Info Artikel Abstrak Abstact,” 2017.

[5] Ivanovic, Milena. 2008. Cultural Tourism. Cape Town : Juta \& Company, Ltd. Sr Di Kafe Kupu-Kupu," vol. VI, no. 2, pp. 1061-1066, 2016.

[6] N. Isnaini, "Karakteristik Penyebab Terjadinya Ketuban Pecah Dini di RSUD Dr. H. Abdul Moelok Provinsi Lampung," J. Kesehat. Holistik, vol. 9, no. 4, pp. 193-196, 2015.

[7] M. Di and B. Jateng, "No Title," vol. 18, no. 01, pp. 43-52, 2019.

[8] A. Manajemen and D. Manajemen, "Pengaruh Pengembangan Karir dan Motivasi Terhadap Kepuasan Kerja Pegawai Pada Kantor Badan Pendapatan Daerah Provinsi Sumatera Selatan Ratna Puji Lestari 1, Suhada 2 2," pp. 248-258, 2013.

[9] S. Ramadanty, "PENGGUNAAN KOMUNIKASI FATIS DALAM PENGELOLAAN HUBUNGAN DI TEMPAT KERJA,” pp. 1-12, 2006.

[10] Salsabila, Yonafia. "Karakteristik Wisatawan Milenial Dalam Meningkat Dayaa Saing Produk Wisata Di Orchid Forest Bandung”(2019) 